\title{
Highlights of the International Symposium on Precious Metals, ISPM'99, Kunming, China 20-24 September 1999
}

Gold and silver were discovered about 6,000 years ago, and all six of the platinum group metals (PGMs) were described for the first time following the identification of platinum in South America in the early years of the eighteenth century (1). The beautiful appearance and excellent resistance to corrosion of these metals has made them favourites for ornaments, jewellery, and currency throughout the world, with gold symbolizing power and wealth ever since 4,000 BC. Since the middle of the nineteenth century these metals have been used in the development of many industrial processes; gold is, however, currently under-developed with respect to its potential in this sense compared with the platinum group metals.

Catalysis based on the PGMs is being used in environmental protection, chemical processing, and new energy sources and gold has the potential to do the same. The overall objective of this conference was to review and discuss the continuing relevance of precious metals and future developments in their use in the 21st Century. This symposium was hosted by the Precious Metals Academic Committee of China, the Gold Institute, North Eastern University and five other Chinese organizations, and sponsored by the Non-Ferrous Metals Society of China.

The opening plenary talk was given by Professor Deng Deguo of the Kunming Institute of Precious Metals and he set the scene for the conference by talking about 'Precious Metals Catalysts for Modern Society in China'. He described how platinum group metals catalysts have been important in the development of industries since the 1950s and are now playing an increasingly important role in environmental control in China. This was followed by a talk by Mike Wyatt, Technical Director-China for Johnson Matthey Catalytic Systems Division in which he discussed the delicate balance between the market price of platinum, palladium and rhodium and technical efficiency in their use. The first three-way catalysts were based on platinum and rhodium, but over the last decade palladium and palladium-rhodium systems have been increasingly used. This in turn has driven up the price of palladium, and palladium thrifting is now important. In the talk entitled 'Recent Developments in Gold Catalysis' presented by David Thompson (Consultant to World Gold Council) the experimental results illustrating the increased activity of supported gold catalysts compared with their platinum metals equivalents, especially at low operating temperatures, were described and potential uses for these catalysts in environmental control, chemical processing and energy generation applications can now be anticipated (2).
Amongst the other plenary talks was one by Joseph Ching, Heraeus Ltd, on the use of precious metal technology in Hong Kong; this included gold electroforming, using $700 \mathrm{~kg}$ per month of potassium gold cyanide and the recent demand for white gold alloys. The Hong Kong jewellery industry has expanded by $50 \%$ in three years to a \$1.5 billion per year level (1997 figures). Professor Xinzhe Lan from Xi'an University of Architecture and Technology talked about environmentally conscious extractive metallurgy; noncyanide reagents for leaching gold were divided into four groups, ie those containing C-, N-, S- and X(halogen)- donor groups. Dr Adalbert Prior (Prior Technologie $\mathrm{GmbH}$, Austria) gave a fascinating talk on the use of new refining technologies developed by the Prior Engineering Group. These include the company's three most recent developments, ie high speed silver electrolysis, the Chloromat and Chloromat/Calcimat processes, and preparative continuous annular chromatography which is currently being developed for gold systems. The Outokumpu process for precious metals refining was described by Olli Järvinen of Outokumpu Wenmec Oy, Finland. Gold is recovered from the gold mud by a rapid hydrochloric acid leaching process and precipitated from solution using sodium metabisulfite. The Pori plant currently produces 4,980 kg gold per annum.

Highlights of the parallel sessions were as follows:

\section{Precious Metals and Human Quality of Environment}

Joseph Ching (Heraeus Ltd, Hong Kong,) gave a talk entitled 'Obviate Environmental Damage Through Integrated Quality Management'. Environmental Concerns are being collectively addressed at the international level through the establishment of the ISO-14000 series of environmental standards. One of the examples of processes being reengineered was to eliminate $\mathrm{NO}_{\mathrm{x}}$ formation during dissolution by using hydrogen peroxide:

$$
4 \mathrm{HCl}+\mathrm{H}_{2} \mathrm{O}_{2}+\mathrm{Au} \rightarrow \mathrm{HAuCl}_{4}+2 \mathrm{H}_{2} \mathrm{O}+\mathrm{H}^{+}
$$

Dental alloys containing gold were described in papers by V. Vasekin and I. Lebedenko of 'Scientific and Industrial Complex Supermetal' and the Moscow Medical Dental Institute and H.R. Ding and X.X. Ma (Fourth Military Medical University, Xi'an and X.Z. Lan of Xi'an University of Architecture and Technology. Supermetal has developed a new all purpose cadmium-free gold solder of 750 fineness; the basic characteristics of the solder are equivalent to traditional cadmium-containing 
solders, ie yellow-gold colour, melting temperature below $800^{\circ} \mathrm{C}$, strong adhesion, corrosion resistance, fluidity, wettability at a level of properties of the $\mathrm{Au} / \mathrm{Ag} / \mathrm{Cd} / \mathrm{Cu} 750$ - 30 gold solder. The Xi'an workers have developed new gold- and silver-palladium alloys which meet the Chinese requirements of biocompatibility, mechanical properties, chemical properties and cast accuracy.

\section{Alloys and Materials}

A plenary lecture entitled 'Progress of Research and Applications of Precious Metals Micro Irregularly Shaped Composites' was given by Li Mingli, Bai Wenchao, Li Yin'ee and Wang Jinming of the Northwest Institute for Non-Ferrous Metals Research, Xi'an, China. Switching contacts and spring push buttons in communications technology, keyboard contacts in computers and electronic devices, and plug connectors in electronic systems require the contact function to be absolutely reliable during longterm use. As they have an excellent stability, gold and high gold content alloys of other precious metals cannot be replaced by any other precious metal.

\section{Refining and Recovery}

There were a number of papers in this section on various aspects of gold refining. The titles were as follows: 'Solvent Extraction of Gold(I) in a Mixed Alcohol-Diluent-Surfactant-Au- $(\mathrm{CN})^{2-}$ System' by Hwang Kwn and Chen Jing of the Kunming Institute of Precious Metals; 'Studies on the Performance of Extracting $\mathrm{Au}(\mathrm{III})$ from $\mathrm{HCl}$ Medium with Petroleum Sulfoxide' by $\mathrm{Gu}$ Guobang, Yi Xiaoyun and Li Yanli of the Institute of Chemical Engineering, South China University of Technology, Guangzhou; and 'Adsorbing Gold with Activated Carbon Fibre from Cyanide and Chloride Solutions' by Lu Yuehua and Shui Chenjing of the Kunming Institute of Precious Metals.

\section{Extraction and Metallurgy}

Amongst the gold papers presented in this section were: 'Optimization of Gold Grade in Production Using Regression and Genetic Algorithm’ by Q.X. Yun, Z.Q. Wang, C.W. Lu and X.Z. Lan of Xi'an University of Architecture and Technology, describing a new approach which has been used in Jinshan gold mine in China; and 'Mathematical Models of Lime-Roasting Pretreatment of Refractory Gold Ore' by Zhang Pengfei and Chen Jin from Changsha Railway University and Central South University of Technology, Changsa describing approaches relevant to the gold ore located in Hunan.

All the papers and posters presented at the Symposium are published in a comprehensive hard-backed conference proceedings book $^{*}$ edited by Professors Deng Deguo, Lan Xinzhe, Yang Yikun and Li Guanfang. Much of the work described from laboratories in China was of an 'upstream' nature (3), being basic research with an industrial orientation, and it was encouraging to see so many young people making the presentations.

David Thompson

\section{REFERENCES}

1 D. McDonald and L.B. Hunt, 'A History of Platinum and its Allied Metals', Europa Publications Ltd for Johnson Matthey, 1982

2 D.T. Thompson, Gold Bull., 1998, 31, 111; 1999, 32, 12

3 E. Konecny, C.P. Quinn, K. Sachs and D.T. Thompson, 'Universities and Industrial Research', The Royal Society of Chemistry, Cambridge, UK, 1995

*The book of Proceedings can be obtained (60 US\$, including postage) from Ms Li Ming, Kunming Institute of Precious Metals, Kunming 650221, Yunnan, China; Fax: +86871515133$)$.

\section{B O O K R E V I E W}

\section{Hallmark - A History of the London Assay Office}

By J S Forbes, Unicorn Press,

London, 1999, pp. 367.

ISBN 0906290260 Price £35

Hallmarks serve as a guarantee of precious metal content and represent an early form of consumer protection. The idea originated with the invention of coinage by the Lydians of Asia Minor sometime in the seventh century BC. By stamping fixed weights, or coins, of precious metal with their distinctive mark, the minting authority sought to provide an assurance of their value. The Romans occasionally marked ingots of gold and silver with official stamps guaranteeing purity and, from the late fifth century $\mathrm{AD}$, similar marks were applied to wrought metal. The practice of hallmarking silverware was introduced in France in 1275 and it spread to much of western Europe by the early fourteenth century.

The foundations of the hallmarking system in England were laid by the passing of a statute of Edward I in 1300, which decreed that all silver articles had to be up to the sterling standard of 11 troy ounces and 2 pennyweights (equivalent to a 925 millesimal purity). This quality had to be demonstrated by an assay undertaken by "the guardians of the craft," who would stamp the silver article with a leopard's head as a mark of conformance. In 1327 , the goldsmith's guild was granted its first charter by Edward III but it was in 1478 that the Assay Office was consolidated as a permanent institution with the appointment of Christopher Elyot as the first full-time, salaried assayer. Remarkably, the Assay Office has occupied the same site within the Goldsmith's Hall complex close to 